\title{
Endovascular versus Open Repair for Abdominal Aortic Aneurysm
}

\author{
Shehab Ahmed Elsayed ${ }^{1}$, Omar Elmokhtar ${ }^{1}$ MD and Abd-Elaziz Ahmed Abd-Elhafez ${ }^{1}$ MD
}

CorrespondingAuthor:

Elsayed, Shehab Ahmed

shepo.sa@gmail.com

Received for publication, April 14, 2020; Accepted, April 14, 2020; published online, July 13, 2020.

Copyright 2020 The Authors published by Al-Azhar University, Faculty of Medicine, Cairo, Egypt. All rights reserved. This an openaccess article distributed under the legal terms, where it is permissible to download and share the work provided it is properly cited. The work cannot be changed in anyway or used commercially.

doi: $\underline{10.21608 / a i m j .2020 .25860 .1170}$

Department of Vascular Surgery - Faculty of Medicine - Al-Azhar University

\begin{abstract}
Background:Abdominal aortic aneurysm (AAA) is a dilation of the aorta due to aortic wall continues to weaken. If left untreated to withstand the forces of the luminal blood pressure resulting in progressive dilatation and rupture with a mortality of $50-80 \%$. Objective: This study aimed to assess the efficacy of Endovascular Aortic Repair (EVAR) against Open Surgical Repair (OSR), of infrarenal AAA regarding type of anesthesia, operative time, blood loss, hospital stay and complications.

Patient and Methods: From January 2016 to December 2017 in AlAzhar University Hospital and Military Hospitals in Cairo, we assigned 30 patients with AAA $\geq 5.5 \mathrm{~cm}$ in diameter to undergo either EVAR or OSR; in two equal groups. Patients were followed up for type of anesthesia, operative time, blood loss, hospital stay, morbidity, mortality and complications.

Results: Regarding comorbidities, $90 \%$ were smokers, $83.3 \%$ were diabetic, $76.7 \%$ had hypertension (HTN), and $66.7 \%$ had ischemic heart disease (IHD). Regarding intra-operative complications, the overall complications rate were $23.3 \%$, with $3.3 \%$ had arrythmias, $3.3 \%$ had distal emboli, and $16.7 \%$ had hemorrhages and received blood transfusion. There was non-significant difference as regards gender, marital status, smoking and Diabetes Mellitus between the 2 groups. Comparative study between the 2 groups revealed significant increase in age, HTN and IHD in EVAR group, compared to OSR group, with significant statistical difference. Comparative study between the 2 groups revealed significant decrease in AAA size and operative time in EVAR group, compared to OSR group, with significant statistical difference. Comparative study between the 2 groups revealed nonsignificant difference as regards intra-operative complications and blood transfusion. Comparative study between the 2 groups revealed significant decrease in Intensive Care Unit (ICU) and ward stay in EVAR group; compared to OSR group. Conclusion: EVAR compared to conventional surgery has some benefits, such as, lower hospital stay, ICU stay, blood loss, rates of hospital mortality, rates of complications and reintervention.

Keywords: Hypertension; Abdominal Aortic Aneurysm; AAA; EVAR
\end{abstract}

Disclosure: The authors have no financial interest to declare in relation to the content of this article. The Article Processing Charge was paid for by the authors.

\section{INTRODUCTION}

Abdominal aortic aneurysm (AAA) is a dilation in which the aortic diameter is $\geq 3.0 \mathrm{~cm}$. If left untreated, the aortic wall continues to weaken and becomes unable to withstand the forces of the luminal blood pressure, resulting in progressive dilation and rupture, a catastrophic event associated with a mortality of $50-80 \%$. $^{1}$

Historical data have shown that ruptures are especially likely to occur with aneurysms measuring $\geq 6 \mathrm{~cm}$ in diameter, but there are so many exceptions and several randomized clinical trials have been done in an attempt to determine whether smaller aneurysms should be repaired electively as soon as they are discovere. ${ }^{2}$
Endo Vascular Aortic Repair (EVAR) is widely used for treating infra-renal aneurysm larger than $5.5 \mathrm{~cm}$. when compared with open surgical repair. Endovascular aortic repair reduces the 30-day mortality risk from $4.7 \%$ to $1.7 \% .^{3}$

Open surgical repair (OSR) by means of laparotomy or retroperitoneal approach, and replacement of the aneurysmal aortic segment with a synthetic graft had been the mainstay of therapy for over 40 years. Given its long-term durability, open repair has traditionally been offered to patients with a moderate life expectancy. The major disadvantage of open repair has been an associated 30 -day mortality rate of $4 \%$ to $5 \%$, and even up to $8.2 \%$ in some series. $^{4}$

However, EVAR is increasingly used in patients with suitable aorto-iliac anatomical features. ${ }^{5}$ 
EVAR was introduced as a less aggressive treatment of AAA for patients ineligible for open repair. ${ }^{6}$

This study aimed to assess the efficacy of EVAR against OSR, of infra-renal AAA, regarding type of anesthesia, operative time, blood loss, hospital stay and complications.

\section{PATIENT AND METHODS}

In this retrospective experimental study From January 2016 to December 2017 in Al-Azhar University Hospital and Military Hospitals in Cairo, we assigned 30 patients with large abdominal aortic aneurysms ( $\geq 5.5 \mathrm{~cm}$ in diameter) to undergo either endovascular or open repair; 15 patients were assigned to each group. Patients were followed for type of anesthesia, operative time, blood loss, hospital stay, morbidity, mortality and complications.

Inclusion criteria: Patient within age group of 50 to 80 years old, with aortic size more than $5.5 \mathrm{~cm}$, and with suitable anatomically for EVAR, and the patients were fit for open surgical repair.

Exclusion criteria: Patients with aortic aneurysm less than $5 \mathrm{~cm}$ in size, or unfit for open surgical repair due to general causes, or the aneurysm in unsuitable anatomically for EVAR, or there were rupture or dissection .

For every patient, the following were required: Medical history and complete physical examination, routine laboratory investigations (complete blood picture, coagulation profile, and kidney function tests), and radiological investigations (CT Angiography on abdominal aorta, and ECHO.( Study Procedures: General anasethia for open repair, and spinal or general anasethia for EVAR.

Surgical repair was either by Trans-peritoneal approach or Extra-peritoneal approach. Then Endovascular repair.

Statistical Analysis: Data entry, processing and statistical analysis was carried out using MedCalc ver. 18.2.1 (MedCalc, Ostend, Belgium). Tests of significance (Mann-Whitney's, Chi square tests, logistic regression analysis and Spearman's correlation) were used. Data were presented and suitable analysis was done according to the type of data (parametric and non-parametric) obtained for each variable. P-values less than $0.05(5 \%)$ was considered to be statistically significant. P- value: level of significance, $\mathrm{P}>0.05$ : Non-significant (NS), $\mathrm{P}<0.05$ : Significant (S), $\mathrm{P}<0.01$ : Highly significant (HS).

\section{RESULTS}

The mean age of all patients was $67.13 \pm 7.9$ years. Regarding gender of the patients, the majority of patients were $90 \%$ males; while $10 \%$ were females. Regarding marital status, $83.3 \%$ were married, $13.3 \%$ were single, while $3.3 \%$ were widowers. Regarding comorbidities, $90 \%$ were smokers, 83.3\% had DM, 76.7\% had HTN, and $66.7 \%$ had IHD (Table1).

The mean AAA size was $7.65 \pm 1.05 \mathrm{~cm}$, and the mean operative time was $168.6 \pm 52.3 \mathrm{~min}$. Regarding intra-operative complications, the overall complications rate was $23.3 \%$, with $3.3 \%$ had arrhythmias, $3.3 \%$ had distal emboli, and $16.7 \%$ had hemorrhages and received blood transfusion (Table2).

The ICU stay was $2.2 \pm 1.7$ days, and the mean ward stay was $3.36 \pm 2.05$ days, with $10 \%$ of patients received post-operative blood transfusion. Regarding (1-week) post-operative complications, the overall complications rate was $10 \%$, with $6.7 \%$ had groin infection, and 3.3\% had chest infection. Regarding (1-month) post-operative complications, the overall complications rate was $20 \%$, with $6.7 \%$ had renal impairment and seroma, and 3.3\% had surgical hernia and wound dehesins. Regarding (1year) post-operative complications, the overall complications rate was $10 \%$, with $6.7 \%$ had chronic kidney disease (CKD), and 3.3\% had surgical hernia (Table3).

\begin{tabular}{|c|c|c|}
\hline \multicolumn{2}{|c|}{ Variables } & \multirow{2}{*}{$\begin{array}{r}\text { Frequency }(\%) \\
67.13 \pm 7.9 *\end{array}$} \\
\hline & Age (years) & \\
\hline \multirow[t]{2}{*}{ Gender } & Female & $3(10 \%)$ \\
\hline & Male & $27(90 \%)$ \\
\hline \multirow{3}{*}{$\begin{array}{r}\text { Marital } \\
\text { Status }\end{array}$} & Married & $25(83.3 \%)$ \\
\hline & Single & $4(13.3 \%)$ \\
\hline & Widow & $1(3.3 \%)$ \\
\hline \multirow{4}{*}{$\begin{array}{r}\text { Co- } \\
\text { morbidities }\end{array}$} & Smoking & $27(90 \%)$ \\
\hline & DM & $25(83.3 \%)$ \\
\hline & HTN & $23(76.7 \%)$ \\
\hline & IHD & $20(66.7 \%)$ \\
\hline
\end{tabular}

Table 1: Basic clinical data among 30 AAA patients.

* Mean \pm SD. HTN: hypertension, DM: diabetes mellitus, IHD: ischemic heart disease.
Variables

Frequency (\%)
$7.65 \pm 1.05 *$

$168.6 \pm 52.3^{*}$

$5(16.7 \%)$

$7(23.3 \%)$

$1(3.3 \%)$

$1(3.3 \%)$

$5(16.7 \%)$
Table 2: Pre and Intra Operative data among 30

AAA patients.

$*$ Mean \pm SD 


\begin{tabular}{|c|c|c|}
\hline \multicolumn{2}{|c|}{ Variables } & Frequency $(\%)$ \\
\hline \multicolumn{2}{|c|}{ ICU stay (days) } & $2.2 \pm 1.7 *$ \\
\hline \multicolumn{2}{|c|}{ Ward stay (days) } & $3.36 \pm 2.05 *$ \\
\hline \multicolumn{2}{|c|}{ Blood transfusion (post-operative) } & $3(10 \%)$ \\
\hline \multirow{3}{*}{$\begin{array}{c}\text { Complications } \\
\text { (1-week post-operative) }\end{array}$} & Complications rate & $3(10 \%)$ \\
\hline & $-\quad$ Chest infection & $1(3.3 \%)$ \\
\hline & - $\quad$ Groin infection & $2(6.7 \%)$ \\
\hline \multirow{5}{*}{$\begin{array}{c}\text { Complications } \\
\text { (1-month post-operative) }\end{array}$} & Complications rate & $6(20 \%)$ \\
\hline & - $\quad$ Renal impairment & $2(6.7 \%)$ \\
\hline & Seroma & $2(6.7 \%)$ \\
\hline & Surgical hernia & $1(3.3 \%)$ \\
\hline & - $\quad$ Wound dehesins & $1(3.3 \%)$ \\
\hline \multirow{3}{*}{$\begin{array}{c}\text { Complications } \\
\text { (1-year post-operative) }\end{array}$} & Complications rate & $3(10 \%)$ \\
\hline & $-\quad$ CKD & $2(6.7 \%)$ \\
\hline & Surgical hernia & $1(3.3 \%)$ \\
\hline
\end{tabular}

Table 3: Post-operative data among 30 AAA patients.

*Mean \pm SD. CKD: chronic kidney disease.

Comparative study between the 2 groups revealed significant increase in age, HTN and IHD in EVAR group, compared to OSR group. There was a non-significant difference as regards gender, marital status, smoking and DM (Table 4).

\begin{tabular}{|c|c|c|c|c|}
\hline \multirow[t]{3}{*}{ Variable } & \multirow[t]{2}{*}{ Groups } & $\begin{array}{l}\text { EVAR group } \\
(15)\end{array}$ & $\begin{array}{l}\text { OSR group } \\
\text { (15) }\end{array}$ & Mann-Whitney's U test \\
\hline & & Median (IQR) & Median (IQR) & $P$ value \\
\hline & Age (years) & $72(66.7-77)$ & $61(58.2-69)$ & 0.005 \\
\hline \multirow{2}{*}{\multicolumn{2}{|c|}{ Variables }} & \multirow{2}{*}{$\begin{array}{l}\text { EVAR group } \\
\text { (15) }\end{array}$} & \multirow{2}{*}{$\begin{array}{l}\text { OSR group } \\
\quad \text { (15) }\end{array}$} & Chi square test \\
\hline & & & & $\mathrm{P}$ value \\
\hline \multirow[t]{2}{*}{ Gender } & Female & $2(13.3 \%)$ & $1(6.7 \%)$ & \multirow[t]{2}{*}{$>0.05$} \\
\hline & Male & $13(86.7 \%)$ & $14(93.3 \%)$ & \\
\hline \multirow[t]{3}{*}{ Marital Status } & Married & $11(73.3 \%)$ & $14(93.3 \%)$ & \multirow[t]{3}{*}{$>0.05$} \\
\hline & Single & $3(20 \%)$ & $1(6.7 \%)$ & \\
\hline & Widow & $1(6.7 \%)$ & $0(0 \%)$ & \\
\hline \multirow[t]{4}{*}{ Co-morbidities } & Smoking & $14(93.3 \%)$ & $13(86.7 \%)$ & $>0.05$ \\
\hline & DM & $13(86.7 \%)$ & $12(80 \%)$ & $>0.05$ \\
\hline & HTN & $15(100 \%)$ & $8(53.3 \%)$ & 0.003 \\
\hline & IHD & $13(86.7 \%)$ & $7(46.7 \%)$ & 0.02 \\
\hline
\end{tabular}

Table 4: Comparison between the 2 groups as regards basic clinical data using Mann-Whitney's U and Chi square tests.

IQR: inter-quartile range.

Comparative study between the 2 groups revealed significant decrease in AAA size and operative time in EVAR group, compared to OSR group. There was a non-significant difference as regards intra-operative complications and blood transfusion (Table 5).

\begin{tabular}{|c|c|c|c|c|}
\hline \multirow[t]{2}{*}{ Variables } & \multirow[t]{2}{*}{ Groups } & $\begin{array}{l}\text { EVAR group } \\
\text { (15) }\end{array}$ & $\begin{array}{l}\text { OSR group } \\
\text { (15) }\end{array}$ & $\begin{array}{c}\text { Mann-Whitney's U } \\
\text { test }\end{array}$ \\
\hline & & Median (IQR) & Median (IQR) & $P$ value \\
\hline \multicolumn{2}{|c|}{ AAA Size (cm) } & $7(6.5-7.8)$ & $8(7.6-8.9)$ & 0.014 \\
\hline \multicolumn{2}{|c|}{ Operative time (min) } & $120(120-137)$ & $200(180-240)$ & $<0.0001$ \\
\hline \multirow{2}{*}{\multicolumn{2}{|c|}{ Variables }} & $\begin{array}{l}\text { EVAR group } \\
\text { (15) }\end{array}$ & $\begin{array}{c}\text { OSR group } \\
(15)\end{array}$ & Chi square test \\
\hline & & & & $P$ value \\
\hline $\begin{array}{l}\text { Blood transfusion } \\
\text { (intra-operative) }\end{array}$ & $+\mathrm{ve}$ & $1(6.7 \%)$ & $4(26.7 \%)$ & 0.1485 \\
\hline $\begin{array}{l}\text { Complications rate } \\
\text { (intra-operative) }\end{array}$ & $+\mathrm{ve}$ & $2(13.3 \%)$ & $5(33.3 \%)$ & 0.2029 \\
\hline
\end{tabular}

Table 5: Comparison between the 2 groups as regards Pre and Intra Operative data using Mann-Whitney's U and Chi square tests. 
Comparative study between the 2 groups revealed significant decrease in ICU and ward stay in EVAR group, compared to OSR group. There was a non-significant difference as regards blood transfusion (Table 6).

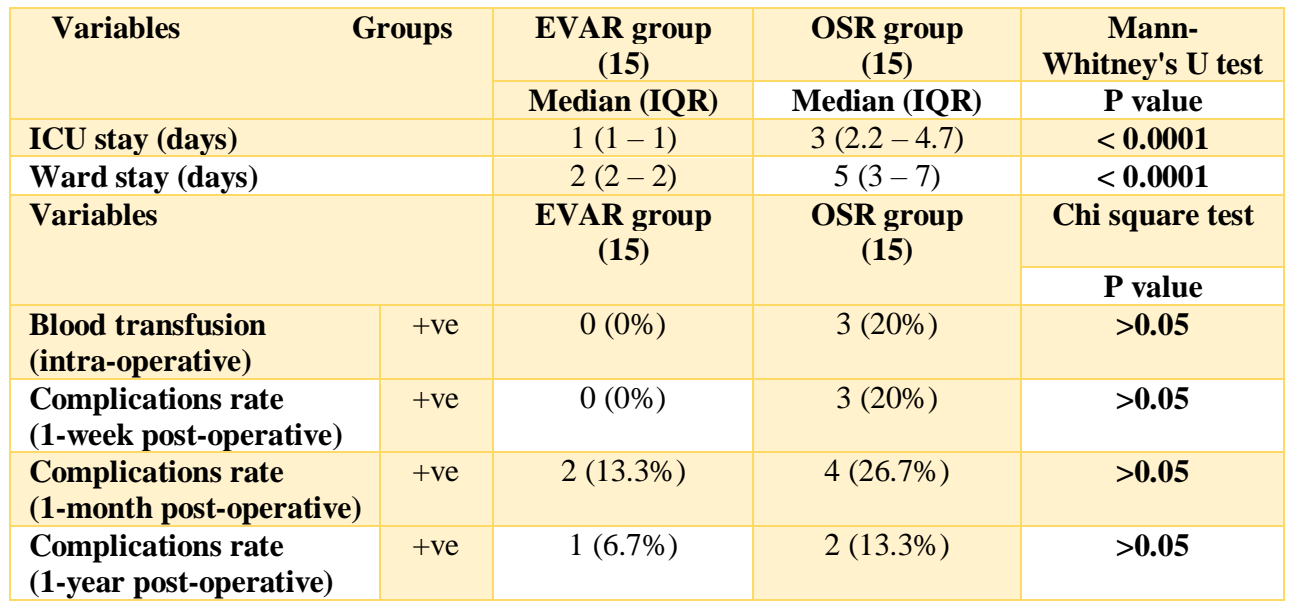

Table 6: Comparison between the 2 groups as regards Post-operative data using Mann-Whitney's U and Chi square tests.

Spearman's correlation analysis showed that AAA size and operative time had significant positive correlation with ICU stay, and age had a significant negative correlation with ICU stay(Table 7).

\begin{tabular}{|l|c|c|c|c|}
\hline \multicolumn{1}{|c|}{ Associated Factor } & \multicolumn{2}{|c|}{ ICU stay } & \multicolumn{2}{c|}{ Ward stay } \\
& $\mathbf{R}$ & $\mathbf{P}$ & $\mathbf{r}$ & $\mathbf{P}$ \\
\hline & & & & \\
\hline Age (years) & -0.441 & 0.014 & -0.362 & 0.049 \\
\hline AAA Size (cm) & 0.444 & 0.013 & 0.321 & $>0.05$ \\
\hline Operative time (min) & 0.890 & $<0.0001$ & 0.839 & $<0.0001$ \\
\hline
\end{tabular}

Table 7: Spearman's correlation analysis for basic clinical/pre and intra operative Factors associated with ICU and ward stay

\section{DISCUSSION}

This comparison is difficult because, although three randomized trials of endovascular abdominal aortic aneurysms repair (EVAR) versus OPEN have been launched (EVAR 1 in the UK, DREAM [Dutch Randomized Endovascular Aneurysm Management] in the Netherlands, and Open Versus Endovascular Repair [OVER] in US Veterans Affairs hospitals), none have been completed: outside of the device trials, the selection of OPEN and EVAR patients in clinical practice understandably differs quite significantly from a clinical trial or clinical practice, EVAR is less stressful than OPEN, so higher-risk patients are most often assigned to it. On the other hand, EVAR is limited by anatomic considerations, so those with complex anatomy usually receive OPEN repair. ${ }^{7}$

Nonrandomized comparison of the outcomes from EVAR and open repair suggest that the incidence of most systemic complications is lower with EVAR. A meta-analysis found a mean incidence of systemic complications of $9 \%$ for EVAR, compared with $22 \%$ in the open surgery. When observations of another meta-analysis on open surgery were compared with the outcome of EVAR in two contemporary studies, the reduced rate of systemic complications was attributable primarily to lower incidences of adverse events affecting the cardiac and pulmonary systems, with reductions from $11 \%$ to $5 \%$ and $5 \%$ to $3 \%$, respectively. These reductions were observed despite the fact that the incidence of preexisting cardiac and other risk factors was significantly higher in the patients treated by EVAR. ${ }^{8}$

In our study, we enrolled 30 patients to compare initial and short term results of Endovascular Aortic Aneurysm Repair (EVAR) and open surgical repair in patients with Abdominal Aortic Aneurysm. As our study was initial experience for EVAR we did our comparison with basic differentiation between new EVAR technique and the classical open surgical technique regarding anethesia technique, procedure time, blood loss, ICU stay, hospital stay, reexploration,arterial complications mortality and morbidity. Regarding the type of anethesia technique; $20 \%$ of the EVAR group was done under regional anethesia compared to $100 \%$ of the open repair which was done under general anethesia which is lower percentage in comparison to other studies which was $40 \%$ in Eurostar done under regional anesthesia ${ }^{8}$

As regards the duration of procedure; EVAR was shorter in duration than open repair consuming about $120 \mathrm{~min}$ compared to $220 \mathrm{~min}$ in open repair, which is 
in fact one of the major advantage which has to be considered in vascular patients as duration of the procedure has major role in the outcome of the patient. Almost similar to the study done by which showed that operative time was shorter in endovascular repair group with (95-120 minutes) compared with (180-300 minutes) in open repair group . ${ }^{9}$

Regarding blood loss and blood transfusion, only $6.7 \%$ of the EVAR group needed blood transfusion compared to $27 \%$ of the open surgical repair group, which shows that in the EVAR technique minimal amount of blood is lost during introduction and deployment of the device, which is Well-documented benefit of EVAR compared to conventional open surgical repair in all studies. ${ }^{10}$

Regarding the ICU stay; in this study it was found that EVAR group was shorter than the open surgical repair group in ICU stay, with ICU stay of 1-2 days versus 3-6 to open repair group which is similar to other studies which showed that ICU stay is shorter than open repair as EVAR trial and Eurostar. Also EVAR group showed less hospital stay duration than open surgical repair group with stay of 1-2 days of the EVAR group versus 3-7 days to open repair which is also similar to other studies that shows EVAR needs less hospital stay than open repair. ${ }^{11}$

Regarding arterial complications were equal, no cases in EVAR group and 2 cases in open repair group one developed lower limb thrombosis on one side managed by fogarty thrombectomy, the other there was renal artery injury managed by direct repair. Other studies show that the systemic complication is more with open surgical repair, a lower incidence of pulmonary complications with EVAR (2.9\% versus $10.9 \%)$, hemorrhage (1.8\% versus $3.4 \%$ ), graft infection $(0.6 \%$ versus $1.1 \%)$, and colonic ischemia $(0.6 \%$ versus $1.1 \%){ }^{12}$

Regarding mortality; we had no mortality after EVAR, or open surgical repair. All other studies show that the mortality is much less in EVAR group than the open surgical repair group. ${ }^{13}$

\section{CONCLUSION}

EVAR compared to conventional surgery has some benefits, such as, lower hospital stay, ICU stay, blood loss, rates of hospital mortality, rates of complications and re-intervention, but EVAR requires training programs still unavailable in many vascular surgery centers. With proper patient selection, EVAR can effectively reach AAA repair goals.

\section{REFERENCES}

1. Kuivaniemi H, Ryer EJ, Elmore JR, Tromp G. Understanding the pathogenesis of abdominal aortic aneurysms. Expert Review of Cardiovascular Therapy, 2015; 13(9):975-87.

2. Hertzer, Norman R. "A primer on infrarenal abdominal aortic aneurysms." F1000Research vol. 61549.23 Aug. 2017, doi:10.12688/f1000research.11860.1
3. Dominique BB, Van Herwaarden JA, Schermerhorn ML and Moll FL. Endovascular treatment of abdominal aortic aneurysms. Nature Reviews Cardiology, 2014; 11(2):112.

4. Mehta M, Paty SK, Byrne WJ, Sternbach Y, Taggert JB and Ozsvath K. Nanotechnology Applications in Vascular Medicine and Surgery. The Clinical Nanomedicine Handbook, 2013; 249-320

5. George AA, Georgiadis GS, Antoniou SA, Kuhan G and Murray D. A meta-analysis of outcomes of endovascular abdominal aortic aneurysm repair in patients with hostile and friendly neck anatomy. Journal of Vascular Surgery, 2013; 57(2): 527-538.

6. Reise JA, Sheldon H, Earnshaw J, Naylor AR, Dick F, Powell JT and Greenhalgh RM. Patient preference for surgical method of abdominal aortic aneurysm repair: postal survey. European Journal of Vascular and Endovascular Surgery, 2010; 39(1):55-61.

7. Rutherford RB. Open versus endovascular stent graft repair for abdominal aortic aneurysms: an historical view. Semin Vasc Surg., 2012; 25(1):39-48.

8. Arya S, Kim SI, Duwayri Y, Brewster LP, Veeraswamy R, Salam A and Dodson TF. Frailty increases the risk of 30-day mortality, morbidity, and failure to rescue after elective abdominal aortic aneurysm repair independent of age and comorbidities. Journal of Vascular Surgery, 2015; 61(2): 324-331.

9. Lee MJ, Daniels SL, Drake TM and Adam IJ. Risk factors for ischaemic colitis after surgery for abdominal aortic aneurysm: a systematic review and observational meta-analysis. International Journal of Colorectal Disease, 2016; 31(7): 1273-1281.

10. Jhaveri KD, Saratzis AN, Wanchoo R and Sarafidis PA. Endovascular aneurysm repair (EVAR)-and transcatheter aortic valve replacement (TAVR)-associated acute kidney injury. Kidney International, 2017; 91(6):131223.

11. Giles KA, Landon BE, Cotterill P, O'Malley AJ, Pomposelli FB and Schermerhorn ML. Thirtyday mortality and late survival with reinterventions and readmissions after open and endovascular aortic aneurysm repair in Medicare beneficiaries. Journal of Vascular Surgery, 2011; 53(1): 6-13.

12. Raux M, Patel VI, Cochennec F, Mukhopadhyay S, Desgranges P, Cambria RP, Becquemin JP and LaMuraglia GM. A propensity-matched comparison of outcomes for fenestrated endovascular aneurysm repair and open surgical repair of complex abdominal aortic aneurysms. Journal of Vascular Surgery, 2014; 60(4): 858-864.

13. Moll FL, Powell JT, Fraedrich G, Verzini F, Haulon S, Waltham M, van Herwaarden JA, Holt PJ, van Keulen JW, Rantner B and Schlösser FJ. Management of abdominal aortic aneurysms clinical practice guidelines of the European society for vascular surgery. European Journal of Vascular and Endovascular Surgery, 2011; 41: 1-58. 